\title{
A DINÂMICA DAS MOBILIZAÇÕES SOCIAIS INDÍGENAS E OS NOVOS DESAFIOS PARA O DIREITO
}

\author{
Rosely Aparecida Stefanes Pacheco* \\ Graduada em Direito e História, Mestre em História, linha de pesquisa História Indígena - \\ Universidade Federal de Mato Grosso do Sul, docente Universidade Estadual de Mato Grosso do Sul, \\ Disciplina Direito Constitucional. \\ e-mail. roselystefanes@superig.com.br
}

RESUMO: Um dos objetivos deste trabalho é desvelar os processos socioculturais em torno da dinâmica das mobilizações sociais que se desenvolvem entre as sociedades indígenas Guarani que habitam o sul do Estado de Mato Grosso do Sul. Este tema fornece uma interface entre o estudo de sociedades indígenas e suas relações com o Estado nacional. As sociedades indígenas, no decorrer dos últimos cinco séculos, experimentaram diversas formas de enfrentamento e resistência. Nessa trajetória do contato conquistaram muitas vitórias, em especial no que se refere às leis que Ihes reconhece o direito às terras, sobretudo a Constituição de 1988. Porém, as leis não têm sido suficientes para garantir-Ihes tais direitos, à medida em que estes são constantemente violados. Para lutar contra essas violações e para fazer com que o Estado assegure suas terras tradicionais, alguns povos indígenas acabam lançando mão de seus próprios meios: reocupam territórios que consideram seus. Neste contexto, estabelecem novos parâmetros para se pensar a diversidade e o Direito, com perspectivas que assegurem a diversidade étnica, demonstrando que os mesmos são sujeitos capazes de permanecerem no presente com projetos de futuro.

PALAVRAS-CHAVE: Mobilizações Sociais. Indígenas. Direito. 


\section{A DINÂMICA DAS MOBILIZAÇÕES SOCIAIS INDÍGENAS E OS NOVOS DESAFIOS PARA O DIREITO}

Um dos objetivos deste trabalho é desvelar os processos históricos e socioculturais que se desenvolvem entre as sociedades indígenas Guarani que habitam o estado de Mato Grosso do Sul. Este tema fornece uma interface entre o estudo de sociedades indígenas em torno de suas demandas territoriais em relação com o Estado nacional no âmbito das conquistas de direitos.

Uma compreensão mais ampla dos desafios que as sociedades indígenas, ainda hoje, enfrentam no campo de seus direitos territoriais, passa, por um desvelar histórico sobre a forma como a questão territorial foi tratada no Brasil, tanto administrativamente quanto juridicamente.

Devemos considerar que os direitos territoriais representam, nos dias atuais, um dos pontos centrais da pauta de reivindicação das sociedades indígenas. Desnecessária se faz uma argumentação mais longa para demonstrar quanto são pertinentes e atuais as reflexões historiográficas sobre os problemas territoriais do país.

Dados recentes apontam que os Guarani Kaiowá e Ñandeva ocupam, no Estado de Mato Grosso do Sul, menos de 1\% de seu território tradicional, encontram-se aldeados em pouco mais de 30 pequenas áreas, (Monteiro, 2003), e que não atendem às suas necessidades mais essenciais.

As sociedades indígenas, no decorrer dos últimos cinco séculos, experimentaram diversas formas de enfrentamento e resistência. Nessa trajetória do contato conquistaram muitas vitórias, em especial no que se refere às leis que lhes reconhece o direito às terras, sobretudo a Constituição de 1988.

As leis não têm sido suficientes para garantir-lhes tais direitos, à medida em que estes são constantemente violados. Portanto, para lutar contra essas violações e para fazer com que o Estado assegure tais direitos, em especial o que diz respeito às suas terras tradicionais, alguns povos indígenas acabam lançando mão de seus próprios meios: reocupam territórios que consideram seus. Neste contexto, estabelecem novos parâmetros para se pensar a diversidade e o Direito, com perspectivas que assegurem a diversidade étnica, demonstrando que os mesmos são sujeitos capazes de permanecerem no presente e com projetos de futuro. 
Neste sentido, devemos considerar que, a dinâmica que as sociedades indígenas, não só do Brasil, como também da América Latina empreenderam, na luta pelos seus direitos, devem em grande parte seus sucessos e sua persistência à capacidade de forjar alianças entre diferentes etnias e povos com outros movimentos sociais, com ONGs e com movimentos de solidariedade internacional.

O surgimento de mobilizações e manifestações indígenas no Brasil está diretamente relacionado com os movimentos étnicos que, a partir da década de 1970, emergem em diversos países da América Latina. No Brasil, foi basicamente a partir desta década (1970), que as diversas mobilizações indígenas alcançaram repercussão junto à opinião pública nacional e internacional. Neste momento, alguns setores da sociedade acreditavam que o fim desses povos era eminente. Foi nesse contexto e na expectativa de se insurgir contra todo esse quadro desfavorável, que as sociedades indígenas iniciaram um intenso e profundo processo de articulações, fortalecimento da auto-estima e organização das lutas. E um dos principais motivos dessas mobilizações foi a luta pela terra.

Assim, em decorrência de denúncias sobre a trágica situação vivida pelos povos indígenas, mais uma vez o governo foi obrigado a ceder a pressões em favor dos direitos dos índios. Sancionando em dezembro de 1973, a Lei no 6.001, o Estatuto do Índio. A partir de então, os povos indígenas, inclusive aqueles cujos aldeamentos haviam sido declarados extintos e totalmente esbulhados na segunda metade do século XIX, ganharam novo ânimo para continuar a luta, quer pela recuperação, quer pela proteção e pelo reconhecimento de seus territórios.

O Estatuto chegou a fixar prazo para que todas as terras indígenas estivessem demarcadas, que seria de cinco anos. Na realidade isso nunca iria se confirmar, pois em vez de seu cumprimento, o que se teve foi o anúncio pelo governo de "solução" para o problema que seria através da "emancipação" por decreto das comunidades indígenas, que assim ficariam desprovidas de seus direitos territoriais.

Oliveira (1998), por sua parte, esclarece ainda que, o Estatuto do Índio foi produzido por um círculo fechado de juristas que incorporava os ideais protecionistas e integracionistas vigente à época, garantindo aos índios proteção especial por meio da tutela do Estado, até que assimilassem a cultura da sociedade envolvente e fossem definitivamente absorvidos por esta sociedade. 
Quanto a participação de significativa parcela da sociedade civil no movimento indígena, e o diálogo estabelecido por esta sociedade deve-se sobremaneira, no âmbito Latino americano, conforme aponta Santos (1989), às críticas dos efeitos etnocidas das políticas desenvolvimentistas, que tiveram na Reunião de Barbados, em 1971, e na Reunião de Peritos sobre Etnodesenvolvimento e Etnocídio na América Latina, realizada em dezembro de 1981, em São José da Costa Rica, eventos especiais na formulação de propostas para um "desenvolvimento alternativo", marcado por projetos de futuro próprios às sociedades indígenas.

As alianças e as discussões efetuadas entre índios e setores da sociedade civil propiciaram às condições políticas para a criação de entidades representativas das sociedades indígenas.

Lima (2002), atenta para o fato de que, foi a partir desse quadro, não mais restrito ao aparelho indigenista e a uma forma difusa e ingênua da opinião pública, como nas décadas de 1950 e 1960, que a idéia de demarcação de terras indígenas afirmou-se como moto. A constatação do total despreparo e da inépcia da Funai, no tocante a essa e a outras questões prementes à vida dos povos indígenas no Brasil, estimulou variados esforços de mapeamento, como os do CIMI e os do programa Povos Indígenas no Brasil, do Centro Ecumênico de Documentação e Informação (Cedi), além de trabalhos de cunho analítico.

No Brasil, muitos intelectuais criariam e se instalariam em ONGs destinadas ao exercício de formas de ação embasadas em referenciais da Antropologia Social. Essa movimentação criou, aos poucos, associações civis de defesa aos índios e outras ONGs surgidas em torno da década de 1980. De acordo com Lima (2002), associações como essas, criadas durante o período de governo autoritário no País, talvez tenham sido uma das formas privilegiadas de questionamento do regime militar, não existindo dúvidas que durante os anos setenta as situações vividas pelas diversas sociedades indígenas, serviram para fundamentar a resistência e a luta que vários segmentos da sociedade civil empreenderam pelo país, visando alcançar sua redemocratização.

Não obstante o ano de 1985 marcaria o início do primeiro governo civil após vinte anos de governos militares. Com esse novo governo, debater-se-iam proposta de reforma agrária, compromisso eleitoral em que a demarcação de terras indígenas 
foi item fundamental. O Ministério da Reforma e do Desenvolvimento Agrários (Mirad) passaria a ter assento na reunião do então fórum deliberativo no tocante a terras indígenas. Dentro do Mirad seriam criadas a Coordenadoria de Conflitos Agrários e a Coordenadoria de Terras Indígenas. Paralelamente para defesa de interesses indígenas, passar-se-ia a invocar a Procuradoria Geral da República, cuja competência nessa área específica seria paulatinamente constituída e, por fim, inscrita na Constituição de 1988.

Seria sob essa conjuntura complexa, que o processo constituinte transcorreria, com tentativas marcantes de defesa da idéia, sempre pronta a ser retomada, de que há muita terra para pouco índio. Por outro lado existia um grupo pró-índio atuando na Constituinte, que teria vitórias significativas no tocante ao capítulo que aborda as populações indígenas.

Tanto na esfera nacional quanto na internacional, podemos perceber alguns avanços em termos do reconhecimento de direitos coletivos indígenas. No plano internacional, foi feita uma revisão da Convenção 107 sobre populações indígenas e tribais, aprovada pela Organização Internacional do Trabalho (OIT) em Genebra em 1957, cujos referenciais ainda eram assimilacionistas e integracionistas, inspirando e legitimando legislações e políticas entre os países signatários (entre eles o Brasil), que articuladas a projetos de desenvolvimento nacionais e regionais, passaram a legitimar os propósitos desenvolvimentistas que alguns dirigentes queriam impor ao Brasil.

Ainda no plano internacional, em 1989, a Conferência Internacional da OIT concluiu uma discussão de três anos, com a participação de inúmeros representantes de organizações indígenas e governamentais, aprovando a Convenção ํo 169. Esta, diferentemente da Convenção № 107, onde os indígenas não foram ouvidos, representou um enorme avanço no reconhecimento dos povos indígenas como sujeitos coletivos, com identidade étnica específica e direitos históricos imprescritíveis. Esta Convenção procura definir detalhadamente, além dos direitos dos povos indígenas, os deveres e as responsabilidades dos Estados na sua salvaguarda.

A revisão das normas internacionais sobre os povos indígenas coincidiu com o processo de revisão da legislação constitucional brasileira, que de maneira geral partilham dos mesmos propósitos. 
Não obstante, as conquistas a nível internacional ainda na década de 80 , com o crescente processo de organização e de articulação dos povos indígenas, aumentou a participação dos índios em diversas instâncias e alianças com segmentos da sociedade civil e com setores populares que procuravam se reorganizar. Representantes indígenas estiveram presentes em congressos de trabalhadores rurais, da Central Única dos Trabalhadores e do então nascente Movimento dos Sem Terra, dentre outros. Por sua vez, representantes de várias organizações apresentaram sua solidariedade, onde apoios e alianças foram sendo consolidados no interior do movimento popular, culminando na promulgação da Constituição de 1988.

Importante destacar que, desde a década de 1990, está em trâmite no Congresso Nacional Estatuto das Sociedades Indígenas, apresentado para garantir a execução da Constituição referente aos direitos indígenas, este projeto sugere a revisão do Estatuto do Índio, Lei ํo. 6.001/73.

Aparentemente, este novo projeto de lei garante novos direitos as sociedades indígenas, porém não podemos nos esquecer que existem muitas divergências que estão postas entre os interesses das sociedades indígenas e os interesses políticos e econômicos de setores da sociedade. Entre eles podemos citar os interesses de grupos econômicos como as madeireiras e as mineradoras. Os interesses são tantos que até hoje o Estatuto das Sociedades Indígenas ainda não foi aprovado.

O que se observa é que, além de estreitarem relações, as alianças indígenas, desencadearam ações conjuntas e cooperações com Igrejas, organizações não-governamentais, entidades de apoio à causa indígena entre outros. Desta forma, o movimento indígena experimentaria variadas formas de organizações,

O movimento indígena brasileiro é mais do que uma resposta meramente reativa às condições e estímulos externos. [...] Deve-se ter em mente que os povos indígenas têm uma longa experiência de andar alinhados em trilhos sinuosos. O que, para um pensamento ocidental, pode parecer desvios à toa, pode verdadeiramente representar o caminho mais curto entre dois pontos, proporcionando-nos lições inesperadas de produtividade. (RAMOS, 1997 p.53 apud NEVES 2003 p. 120) 
Observa-se a partir daí, investidas reivindicatórias mais incisivas dos índios no tocante a reocupação de seus territórios tradicionais. Os Guarani, em Mato Grosso do Sul, passaram a estabelecer novas estratégias para reivindicar a conquista de terras que consideravam suas: e em ritmo próprio tiveram avanços significativos. Ademais, os povos indígenas e suas organizações têm mostrado não apenas uma grande e histórica capacidade de resistência, mas uma vitalidade e criatividade que vêm surpreendendo a todos, projetando-se no cenário público, deixando suas marcas em conquistas importantes na Constituição de 1988, traduzindo-se na construção de espaços plurais de representação de atores coletivos, hoje reconhecidos como interlocutores válidos no cenário político nacional.

As ações que aparentemente isoladas das diversas comunidades, transformam-se, em eventos políticos capazes de aglutinar populações de várias comunidades alterando significativamente a maneira como, até então vinha sendo tratado o direito destas comunidades às suas terras

\section{As grandes assembléias - Aty Guasu como dinâmica de mobilização}

É necessário considerarmos que, em toda política indigenista, em relação aos Guarani Kaiowá e Ñandeva do Estado de Mato Grosso do Sul, pouca ou nenhuma importância foi dada a temas determinantes como a questão da terra. Isto de certa forma levou-os a refletirem sobre a inviabilidade do modo de vida nas reservas, articulando-se discussões internas que culminariam na alternativa de reocupação de suas áreas tradicionais.

Tradicionalmente, a prática indigenista aplicada aos Guarani Kaiowá e Ñandeva parte de conceitos de aculturação e integração. Isto tem se revelado desde a criação do SPI em 1910 até os dias atuais, quando das iniciativas forçadas e mal planejadas dos órgãos indigenistas ou missionários; conforme observa Almeida (2003), estas práticas desconsideram especificidades étnicas, não garantem as terras indígenas, encobrem e desconhecem conflitos, e ainda, estabelecem alianças com interesses contrários aos do Kaiowá e Ñandeva ou desconsideram sua capacidade organizativa. 
Nessa perspectiva, apontamos a importância das assembléias - Aty Guasu ${ }^{1}$ como algo que atualiza as tradições e se faz presente posicionando o grupo étnico diante dos fluxos culturais. Nestes momentos de reivindicação de territórios, estas asssembléias - Aty Guasu - têm um papel de grande relevância, à medida que, itens de cultura fluem como significantes e são apropriados para se tornarem signos, para serem significados como tradições. Desta forma, os conteúdos das tradições são criados e recriados periodicamente de forma contextual ou situacional, e inclusive a partir de enxertos de cultura externos.

As aty guasu são reuniões, organizadas pela comunidade com a presença de lideranças tradicionais. São eventos de grande importância para os Guarani, que esperam ansiosos pela sua realização. Nessas reuniões, conforme argumentam, todos os índios têm direito à palavra e ao encaminhamento de questões. Nestes momentos de "representações de cultura", os Guarani, de certa forma, exibem suas tradições tornando-se conhecidos (fazendo-se visíveis).

Ao analisar as grandes assembléias, Almeida (2001), relata que, o marco da reação Guarani contra todo o processo de espoliação e aldeamento que vinham sofrendo, foi a discussão do problema fundiário, apresentada na Grande Assembléia Geral realizada em 1977, promovida pelo projeto Kaiowá-Ñandeva. Esta assembléia serviu para mobilizar os indígenas e seus aliados no intuito de reverem toda a situação fundiária.

As assembléias ganharam força e os Guarani Kaiowá e Ñandeva perceberam que esta era uma estratégia possível, uma vez que através de uma organização interna, juntamente com o apoio de alguns colaboradores, poderiam romper com todo um processo ao qual vinham sendo submetidos.

Podemos perceber que nas Aty Guasu realizadas recentemente nos anos 2004 e 2005, uma das propostas principais destas reuniões era a de levar ao conhecimento de todos os Guarani e sociedade envolvente presentes, conhecimentos sobre os processos judiciais em torno das terras demandadas, bem como articular comissões que pudessem se dirigir até a cidade de Brasília/DF, para efetuarem contatos com órgãos governamentais.

\footnotetext{
${ }^{1}$ De acordo com estudos de Brand, as últimas aty guasu teriam ocorrido em 1904, 1936, 1945 e tinham como objetivo principal discutir ameaças ao território.(Brand, 1997, p.14)
} 
Neste contexto, observamos, a importante participação das lideranças indígenas no "campo de intermediação", uma vez que, nos últimos anos passaram a assumir uma configuração mais incisiva, trazendo um discurso mais contundente à causa indígena (BOURDIEU, 2003).

Nessa dinâmica, as lideranças emergem no contexto de contato e passam a transitar mais sistematicamente na sociedade não-indígena. Desta forma, os indígenas passam a utilizar, na perseguição de seus objetivos de significação "interna", toda a influência e prestígio advindos do acesso ou controle de bens e poderes possibilitados pelo apoio dos agentes "externos". Arruda assim observa:

Ao mesmo tempo em que as agências passam a participar do jogo político interno na perseguição do apoio indígena, os índios passam a se utilizar das agência na luta por objetivos que são, simultaneamente, representativos de interesses de grupos na luta política interna e do conjunto do povo ante a sociedade nacional (ARRUDA, 2001, p.57).

Ao contrário do que muitos apregoam, os índios não são manipulados por organizações que os incitam a "invadir" terras, fazendo-os crer que as áreas lhes pertencem. Tentar explicar os movimentos de reocupação de territórios através da perspectiva de que os mesmos são manipulados por agentes externos, é desconsiderar os indígenas como sujeitos históricos capazes de realizar mudanças. O processo de mobilização é endógeno, partindo da própria comunidade indígena, que resolveu por meios próprios reocupar um território que consideram pertencer a esta comunidade.

\section{A Constituição Federal de 1988 e as sociedades indígenas}

Por certo, o processo histórico de expansão das fronteiras não se fez sem conflitos. Foi necessário um longo período de lutas para que os direitos indígenas fossem assegurados. Nesse sentido, a Constituição de 1988 foi um marco importante, pois na expectativa de garantir e conquistar direitos na Constituição foi que os povos indígenas escreveram parte de sua história, alcançando direitos até então nunca vislumbrados.

A mudança profunda que a Constituição de 1988 introduziu foi o reconhecimento de direitos permanentes aos índios. Ela abandona a tradição 
assimilacionista e integracionista vigente até então, e encampa a idéia de que os índios são sujeitos presentes e capazes de permanecer no futuro.

Esses direitos constitucionais estão inscritos em um capítulo próprio - Dos Índios - e em uma dezena de dispositivos que contêm referências específicas a direitos indígenas, constante de outras partes da Constituição.

A Constituição de 1988 consagrou, com ênfase, os direitos dos índios e de suas comunidades, inclusive $\mathrm{o}$ direito à identidade cultural e $\mathrm{o}$ direito de ocupação permanente da terra e a exclusividade no uso de seus recursos e na exploração de suas riquezas. A nova visão consiste no reconhecimento pelo Estado brasileiro do direito dos índios continuarem a existir como diferentes. Reconhece os índios, suas comunidades e organizações como entidades capazes de conduzir o seu próprio destino e de serem representantes legítimos na defesa de seus próprios direitos e interesses. Essa perspectiva aboliu o regime de tutela, exercida pelo órgão indigenista e colocou novos parâmetros sobre os quais o Estado deve se relacionar com os povos indígenas. Assim, a nova Constituição lançou novas bases para o estabelecimento de um projeto político plural, fundado na diversidade étnica do País.

Do ponto de vista da garantia desses direitos, dois pontos merecem destaque, conforme sustenta Dallari (2001), quais sejam: a atribuição de competência à Justiça Federal para as questões que envolvam direitos de índios. Este procedimento é de suma importância, visto que em vários Estados brasileiros, sobretudo onde há maior número de terras indígenas, era muito forte a influência das elites econômicas e políticas sobre o Poder Judiciário; outro ponto que merece especial referência, diz respeito a atribuição constitucional ao Ministério Público Federal (MPF) para defesa dos direitos dos índios. Segundo o artigo 129, inciso V, uma das funções institucionais do MPF é defender judicialmente os direitos e interesses das populações indígenas.

Trabalhando com notável dedicação, usando de todos os meios legalmente possíveis para repelir invasão de terras indígenas e para recuperação de áreas já invadidas, o Ministério Público Federal tem dado extraordinária contribuição para que tenham efetiva aplicação, as normas constitucionais relativas aos direitos dos índios e de suas comunidades.

No entanto, transcorridos 16 anos de sua promulgação, este conjunto normativo constitucional continua incompleto. A regulamentação do Artigo 231, 
Parágrafo Terceiro e Sexto, que tratam por meio de Leis Ordinárias e Complementar respectivamente, encontra-se à espera de diligência do Congresso Nacional; negligenciando aos indígenas uma importante ferramenta de proteção e de gestão territorial, por meio da normatização da previsão constitucional do aproveitamento dos recursos minerais hídricos e potencial energético, incidentes em suas terras. Outro aspecto importante é a regulamentação da hipótese do "relevante interesse público da União", que excepcionaliza a ocupação de terras indígenas ou a exploração dos recursos naturais por terceiros, que atenderiam em tese, aos projetos governamentais, tais como os do setor elétrico, transporte entre outros.

A falta de regulamentação de tais dispositivos compromete a coerência e o sentido de complementaridade entre os artigos e seus parágrafos.

Dada a complexidade dos problemas no plano constitucional, convém não deixar de afirmar, conforme leciona Bobbio (1992, p.63) uma coisa é falar dos novos direitos e cada vez mais extensos, e justificá-los com argumentos convincentes; outra é garantir-Ihes uma proteção efetiva.

Observa-se que, no tocante ao aparelho governamental, não existe um projeto de futuro decorrente de um padrão de diálogos interétnicos e sem novos instrumentos regularizadores das relações com os povos indígenas no Brasil. A tramitação do Estatuto das Sociedades Indígenas desde 1991, é apenas um exemplo de que os governantes não têm envidado esforços para tentar minorar uma situação que esta posta.

Atualmente, um número significativo de comunidades Guarani Kaiowá e Ñandeva encontram-se mobilizadas em torno da demanda de suas terras. Instaurando uma fase inédita no relacionamento entre os indígenas e o Poder Judiciário. Aqueles não estão somente conseguindo dar visibilidade as suas demandas, como também, estão revertendo decisões contrárias a seus direitos, concedidas em juízos de primeira instância. Não dispensando muitas vezes interlocutores nesta tarefa.

Os indígenas vêm apresentando ao Judiciário suas reivindicações e mostrado a situação em que vivem, pois, esta realidade, em grande parte, é desconhecida nos processos judiciais; até porque, abordado sob uma perspectiva interna, o processo judicial se constrói como universo fechado, dotado de lógica 
própria, a lógica jurídica, que, na maioria das vezes, não reflete as realidades sociais e políticas de que trata.

O contato com a situação evidencia aos "aplicadores da justiça" que suas concepções são muitas vezes estereotipadas, e noções como "aldeia", "tribos", "malocas", "aculturados", "que não são mais índios e sim paraguaios"- embora ultrapassadas, são representações operantes no discurso jurídico.

A esse respeito, Bourdieu (2003), nos ensina que a situação judicial funciona como lugar neutro, que opera uma verdadeira neutralização do que está em jogo, sendo que os agentes especializados, enquanto terceiros, introduzem uma distância neutralizante a qual fica bem clara principalmente no caso dos magistrados.

Neste sentido importa argumentar, conforme propõe Wolkmer (2004), sobre a importância de se instaurar uma discussão sobre as formas de produção de direitos a partir da própria prática social. (WOLKMER, 2004, p. 25).

\section{Os indígenas e as novas perspectivas para se pensar o Direito}

O quadro de relações interétnicas no Brasil é muito complexo, principalmente quando nos referimos a novas formas de pensar 0 Direito. Percebemos que há muitos procedimentos estruturais - multisseculares - a dificultar a concretização das legislações que contemplam direitos que dizem respeito as sociedades indígenas.

Porém, com os acontecimentos das últimas décadas, em especial quando nos referimos às mobilizações indígenas em torno de suas demandas territoriais, estas demonstram que tais transformações nos trazem à tona, novos sujeitos e novos cenários, e estes, por sua vez, impõem a construção de novas reflexões para a teoria jurídica em suas dimensões civil, pública e processual, capaz de contemplar o crescente aparecimento de novos direitos, uma vez que, as necessidades, os conflitos e os novos problemas colocados pela sociedade engendram também novas formas de direitos que desafiam e põem em dificuldade a dogmática jurídica tradicional, seus institutos formais e materiais e suas modalidades individualistas de tutela (WOLKMER, 2003, p.03). 
Um dos novos pressupostos que estas demandas nos trazem, diz respeito à força de transformação política que estas empreendem. Não se trata de uma simples mobilização que cessaria no dia em que os indígenas passassem a reocupar todos seus antigos territórios, uma vez que o entendimento que nos é apresentado é o de que, a Terra representa dignidade, participação, cidadania e democracia. Aspectos que não podem ser desprezados quando se trata de um novo pensar sobre o Direito.

Quanto à transformação dos paradigmas legais nos quais estão amparados tanto a doutrina quanto a prática jurídica no Brasil, o professor Wolkmer (2003), argumenta sobre os preceitos jurídicos modernos nascidos na Europa Ocidental entre os séculos XVII e XIX, que foi engendrado por um longo processo interativo de fatores, como: o modo produtivo capitalista, a organização social, a projeção doutrinária liberal-individualista e a consolidação política da centralização estatal. Por certo é que, se estimulou, sob a égide de um Estado-Nação, pretensamente unificado, o processo de integração dos múltiplos sistemas legais sob o fundamento da igualdade de todo os indivíduos perante uma legislação comum. Desta forma, a sociedade moderna européia não só favorece a emergência de uma estrutura centralizada de poder (Estado-Nação Soberano), como edifica uma concepção monista de regulação social e uma racionalização normativa técnico-formalista que tem no Estado a fonte legitimadora do Direito. Impõem-se, neste sentido a teoria e a prática jurídica assentadas sobre uma concepção individualista, patrimonial e científica, em que o Direito expressa o que está na lei escrita, e o Estado, seria a fonte direta e exclusiva de todas as normas sociais válidas (WOLKMER, 2003).

É certo que o grande acontecimento destes últimos anos é sem dúvida a descentralização do Estado. Este termo não deve ser entendido apenas no seu sentido jurídico; houve também uma transferência da soberania do Estado para as coletividades regionais, com um novo conceito político característico de uma sociedade policêntrica, visto que, vivemos um esgotamento do estado provedor.

Neste panorama, os operadores jurídicos, mesmo que timidamente, começaram a dialogar com as diversas áreas tentando compreender novos referenciais epistemológicos sobre os quais pudesse ser construído e fundamentado o Direito, constatando que o Direito moderno se ancorava em obstáculos 
epistemológicos praticamente insanáveis, que pertenciam à sua própria conformação e estruturação.

Esse direcionamento desvela que, direitos de liberdade e direitos sociais não podiam conviver pacificamente num mesmo ordenamento, para ser aplicado por uma mesma jurisdição. Entretanto, esta ordenação epistemológica passou nas últimas décadas do século XX, por um estudo crítico, passando-se a estabelecer novas bases para uma Teoria Crítica do Direito.

Conforme aponta Wolkmer (2003), este movimento, baseado na análise lingüística do discurso jurídico, naquilo que está por detrás da fumaça, estruturado pelo positivismo dogmático, conjuntamente com o expansivo movimento alternativo, seja este de Direito Alternativo, de uso alternativo do Direito ou da Jurisprudência alternativa, e o pluralismo Jurídico provocaram uma consciência generalizada sobre a crise paradigmática do Direito moderno.

Essa transformação de paradigmas legais gera também uma confusão de paradigmas, vivida de maneira conflituosa e cheia de angústias pelos sujeitos que a experimentam. Assim, percebemos que não existem mais juristas "senhores de si"; há um incômodo geral, principalmente no sentido de que é preciso construir um novo diálogo com outras disciplinas, pois, na realidade, temos uma série de eventos, regulamentos, políticas, costumes, crenças, sentimentos, símbolos, procedimentos e conceitos agrupados.

De maneira geral, a concepção positivista predominante nos cursos de Direito reduz o fenômeno jurídico a um conteúdo meramente legalista e formal, o que tem sacrificado em muito as idéias de justiça, eqüidade, igualdade, transformando-se num culto à lei, que juntamente com a crença da neutralidade do judiciário, provocou o alheamento deste Poder ao que, na realidade, se passa com as sociedade(s), conferindo-Ihe indiferença em relação aos conflitos e seu descomprometimento com as injustiças sociais. Isso levou o Poder Judiciário a cair nas armadilhas das instâncias dominantes, funcionando, com freqüência, como mecanismo de controle social, de produção e defesa de uma ordem jurídica mais consagradora de desigualdades do que de liberdades (MACHADO, 1996).

É necessário que se cultive, principalmente nos magistrados, a reflexão sobre a importância da garantia dos direitos fundamentais da pessoa humana. Nas palavras de Rocha, 
Não pode o magistrado manusear o processo como uma máquina, sem enxergar que por trás das páginas dos autos existe vida humana, que merece ser tratada com respeito e dignidade. É necessário ter em mente que por entre cada peça que compõe o caderno processual há um bem jurídico fundamental a ser resguardado. (ROCHA, 1998 p.116).

Portanto, para que os operadores do Direito possam compreender sobre as realidades complexas como a reocupação de territórios indígenas, estes têm que transpor conceitos, já superados, que ainda encontram respaldo nesta ciência, como por exemplo: que o Estado é árbitro imparcial dos conflitos e que o Juiz, investido de poder, pauta-se pela objetividade e neutralidade para a busca da verdade real.

Desta forma é preciso considerar, que o Poder Judiciário tem exercido um papel preponderante na aplicação desses novos direitos, mas mantido uma posição conservadora na maioria das vezes que é chamado a reconhecer os direitos indígenas. Em geral tem sido necessário ir à Justiça para obtê-los.

Importa esclarecer que o surgimento e a existência desses novos direitos devem ser observados a partir das exigências contínuas, locais e particulares da própria coletividade diante das novas condições de vida e das crescentes prioridades impostas socialmente. E, tais direitos, ainda que chamados de novos direitos, não são inteiramente novos, na realidade, como propõem Wolkmer (2003, p.20), novo é o modo de obter direitos que não passam mais pelas vias tradicionaislegislativa e judicial, mas provêm de um processo de lutas específicas e conquistas das identidades coletivas plurais para se tornarem visíveis pelo Estado ou pela ordem pública constituída.

Ademais, se aspiramos uma sociedade realmente democrática, é necessário buscarmos caminhos de articulações baseados no pluralismo legal e cultural de nossas sociedades, bem como em uma redistribuição eqüitativa dos recursos materiais e políticos, pois, conforme observa Yrygoen (2004, p.222), Solo así podremos empezar a vislumbrar un Horizonte Pluralista para nuestras sociedades, promover la justicia, reducir la violência, y caminar hacia uma paz sostenible.

\section{REFERÊNCIAS BIBLIOGRÁFICAS}

ALMEIDA, Rubem Ferreira Thomaz de. Do desenvolvimento comunitário à mobilização política: o Projeto Kaiowá - Ñandeva como experiência antropológica. Rio de Janeiro: Contra Capa Livraria, 2001. 
ALMEIDA, Rubem Ferreira Thomaz de. Texto $1^{\circ}$ Encontro de Etnobiologia e Etnoecologia da Região Centro-Oeste (16-18/06/2003) Dourados-MS.

BOBBIO, Norberto. A Era dos Direitos. Rio de Janeiro: Campus, 1992.

BOURDIEU, Pierre. O poder simbólico. Tradução de Fernando Tomaz. $6^{\text {a }}$ ed. Rio de Janeiro: Bertrand Brasil, 2003.

BRAND, Antonio. O impacto da perda da terra sobre a tradição Kaiowá/Guarani: Os Difíceis Caminhos da Palavra. Pontifícia Universidade Católica - PUC/RS, Porto Alegre novembro de 1997/ Pós Graduação.

DALLARI, Dalmo de Abreu. Conflitos de Direito sobre as terras Guarani Kaiowá. Conselho Indigenista Missionário Regional Mato Grosso do Sul; Comissão Pró Índio de São Paulo. São Paulo: Palas Athena, 2001.

YRYGOEN, Raquel. Vislumbrando um Horizonte Pluralista: Rupturas y retos epistemológicos y políticos. In: Los Desafios de la Interculturalidad: Identidade, Política y Derecho (org.) LUCIÉ, Milka Castro. LOM ediciones Ltda, Santiago/ Chile, 2004.

LIMA, Antonio Carlos de Souza. Questões para uma política indigenista: etnodesenvolvimento e políticas públicas. In: LIMA, Antonio C. Souza e HOFFMANN, Maria Barroso (orgs.). Etnodesenvolvimento e Políticas Públicas: bases para uma nova política indigenista. Rio de Janeiro: Contra Capa Livraria, 2002.

MACHADO, Marcello Lavenere. Justiça para o campo. In: CPT, Conflitos no Campo. Goiânia: Comissão Pastoral da Terra, 1996.

NEVES, Lino João de Oliveira. Olhos mágicos dos Sul (do Sul): lutas contra-hegemônicas dos povos indígenas no Brasil. In: SANTOS, Boaventura de Souza. (org.). Reconhecer para libertar: os caminhos do cosmopolitismo multicultural. Rio de Janeiro: Civilização Brasileira, 2003.

OLIVEIRA, João Pacheco de. (org.) Indigenismo e Territorialização.Rio de Janeiro. Editora Contra Capa, 1998.

ROCHA, Fernando Luiz Ximenes. Direitos Fundamentais na Constituição de 1988. Cadernos de Direito Constitucional e Ciência Política, out./dez. 1998.

SANTOS, Silvio Coelho dos. Povos Indígenas e a Constituinte. Florianópolis: Ed. da UFSC/Movimento, 1989.

WOLKMER, Antonio Carlos (org.). Os "Novos" Direitos no Brasil: natureza e perspectivas: uma visão básica das novas conflituosidades jurídicas. São Paulo: Saraiva, 2003.

WOLKMER, Antonio Carlos. As Necesidades Humanas como Fonte Insurgente de Direitos Fundamentais. In: Revista Veredas do Direito. Jul/Dez. 2004. 